\title{
Ocular Adnexal and Anterior Segment Manifestations of HIV/AIDS Patients as Seen at the HIV Clinic, 45 Nigerian Airforce Hospital Makurdi, Benue State, Nigeria
}

\author{
A Bologi ${ }^{1}$ FMCoph, FW ACS, CO Ojabo ${ }^{2}$ FWACS \\ ${ }^{1}$ Eye Clinic, 45 NAF Hospital Makurdi, Nigeria \\ ${ }^{2}$ Department of Ophthalmology, College of Health Sciences, Benue State University, Makurdi, Nigeria
}

\section{A BSTRACT}

Background: Benue State has the highest rate of sero-prevalence to human immuno virus (HIV) infections among the ten hyper-endemic states in Nigeria. This study evaluates the pattern of ocular adnexal and anterior segment manifestations in HIV/AIDS patients attending the HIV clinic at the NAF Hospital in Makurdi, Benue State and assesses their effects on the visual functions of the patients.

Methods: This is a hospital-based prospective study of all new patients who presented at the HIV clinic between October 2007 and March 2008. Ocular and systemic examinations were carried out and personal data including age, sex, place of abode, occupation and marital status were recorded for each patient.

Results: A total of 322 patients were seen. The male to female ratio was 1:1.50. The age range was $4-68$ years. The prevalence rate of anterior segment/ocular adnexal manifestation was $65.2 \%$. Conjunctival microangiopathy was the commonest ocular adnexal/anterior segment presentation constituting $33.8 \%$ (highest anterior segment manifestation). Iridocyclitis constituted $27.14 \%$, while herpes zoster ophthalmicus accounted for only $3.3 \%$ of the cases. The majority of the patients (95.1\%) had normal visual acuity at presentation to the clinic. Twelve percent had visual impairment, while $5.0 \%$ presented with severe visual impairment.

Conclusion: Conjunctival microangiopathy, iridocyclitis and molluscum contagiosum were the main anterior segment lesions observed in this study. Less than $2 \%$ of the patients had severe visual impairment or blindness at presentation to the clinic.

Key words: HIV, ocular adnexae, anterior segment, visual acuity, HIV hyper-endemic state

\section{INTRODUCTION}

Over 45 million people globally are living with the HIV virus. ${ }^{1}$ The impact of this disease is mostly felt in poor countries in Africa and Asia.Sub-Saharan Africa remains the most seriously affected region, with AIDS still ranking as one of the leading causes of death. More than half $(68 \%)$ of all people who are HIV sero-positive live in sub-Saharan Africa. ${ }^{2}$ Nigeria is the most populous country in sub-Saharan Africa and the $10^{\text {th }}$ most populous in the world. Since the first case of AIDS was reported in Nigeria in 1986, the number of infected persons has been on the increase. The adult HIV prevalence rate has increased from $1.8 \%$ in 1991 to $4.5 \%$ in 1996 . By 2001, the prevalence rate had increased to $5.8 \% .^{3}$

Currently about $3.9 \%$ of adults between 16 and 49 years are living with HIV. ${ }^{4}$ Even though the HIV prevalence rate in Nigeria is much lower than in the East and South African countries, Nigeria being the most populous country on the continent has made HIV syndrome one of the devastating medical problems of modern day sub-Saharan Africa. In South Africa, ${ }^{5}$ one out of every five pregnant women is seropositive for HIV. The projected population of Burkina Faso in 2008 is 15.2 million. The adult $\mathrm{HIV}^{6}$ prevalence was $1.6 \%$ in 2007. A population-based study in $\mathrm{Uganda}^{7}$ reported an HIV prevalence rate of $30 \%$ in 1999 . However, due to government intervention, it dropped to $12.16 \%$ in 2003 .

Since its emergence in Nigeria, this pandemic has systemically permeated every community in the country. The national sero-prevalence rate has increased steadily by over $200 \%$ in the last two decades. HIV / AIDS infection is the new leading cause of death in Nigeria. ${ }^{4,8}$ This, coupled with other social ills such as poverty, has had devastating consequences on the populace. Benue State, in the north central zone of Nigeria, is one of the ten hyper-endemic states for HIV. The state still retains the $1^{\text {st }}$ position nationwide for HIV sero-prevalence. ${ }^{2,4,8}$ Prior to the availability of the highly active retroviral therapy, it was as high as $16.8 \%$.

Since the initial eye conditions in HIV patients were reported more than two and a half decades ago, lots of reports have documented eye disorders affecting an average of $75 \%$ of all patients at some point during the illness. ${ }^{9,10}$ In a series by Serraf, ${ }^{11} 60 \%$ of the patients had one form or 
another of ocular manifestation of HIV-AIDS. A number of ophthalmic manifestations of HIV infection involve the anterior segment. ${ }^{12}$

Kehinde $^{13}$ reported that herpes zoster ophthalmicus (HZO) accounted for $69.6 \%$ in a study conducted in north central Nigeria. This represents the highest ocular finding.

Adegbehingbe ${ }^{14}$ also reported $\mathrm{HZO}$ as the commonest ocular disease seen in his series. Akinsola, working in Lagos, found herpes zoster in $54 \%$ of HIV cases seen in her study. ${ }^{18}$ Earlier studies from the north central, ${ }^{13}$ north west, ${ }^{15}$ east central, ${ }_{1}^{16}$ and south west zones ${ }^{17,18,19}$ of Nigeria reported that ocular adnexal and anterior segment disorders were more prevalent than posterior segment disorders. Ocular disease occurs at different stages of HIV infection. In the same vein, earlier studies have documented regional variations in the spectrum of eye diseases. ${ }^{20}$ To the best of our knowledge, no previous studies have been carried out in the north-central zone of Nigeria to determine the effects of HIV / AIDS infection on the eye. The aim of this study, therefore, was to evaluate the pattern of ocular adnexal and anterior segment manifestation in HIV / AIDS patients and assess their effects on their visual functions.

\section{MATERIAL AND METHODS}

The study recruited all new patients presenting to the HIV clinic between October 2007 and March 2008 for the first time. Visual acuity and ocular examinations were carried out on each patient with emphasis on the ocular adnexea and anterior segment using the loupe and slit lamp. Both upper and lower lids were everted and examined for any pathology. The lacrimal system was assessed by viewing the tear film level under the slit lamp. The conjunctival palpebrae, tarsal and forniceal aspects were all examined under magnification under the slit lamp and detected abnormalities were documented. The cornea was examined, and staining with fluorescien dye was done when indicated. The anterior chamber and the lens were examined under the slit lamp. Pupillary examination was done and pupillary size, shape, and regularity were documented and pupillary light reaction tested. Although applanation tonometry and ophthalmoscopy were carried out on each patient, these two parameters are subjects of another report. Blood samples were taken for full blood count, electrolyte and urea, liver function tests, and fasting blood sugar, and haemoglobin electrophoresis was carried out on each patient.

\section{RESULTS}

A total of 322 patients (table 1) were seen. The male to female ratio was 1:1.50. The patients ages ranged from 4 to 68 years. The prevalence rate of anterior segment/ adnexea ocular manifestation was $65.2 \%$. Conjunctival microangiopathy was the commonest ocular adnexal/anterior segment presentation. It constituted 33.8\% (highest anterior segment manifestation). Iridocyclitis was next accounting for $27.1 \%$, while herpes zoster ophthalmicus was observed in only $3.3 \%$ of the cases (see table 2 ). A majority of the patients (95.1\%) (tables 1 \& 2, fig. 1) had normal visual acuity at presentation to the clinic. Twelve per cent had visual impairment, while $5.0 \%$ presented with severe visual impairment.

Table 1. Findings at initial presentation of patients to the HIV / AIDS clinic

\begin{tabular}{lcc}
\hline & No of patients & $\%$ \\
\hline With ocular lesions & 210 & 65.2 \\
Without ocular lesions & 112 & 34.8 \\
\hline Total & 322 & 100.0 \\
\hline
\end{tabular}

Table 2. Adnexal/anterior segment disorders in patients with ocular lesions

\begin{tabular}{|c|c|c|}
\hline & $\begin{array}{c}\text { No of } \\
\text { patients }\end{array}$ & $\%$ \\
\hline Conjunctival microangiopathy & 71 & 33.8 \\
\hline Iridocyclitis & 57 & 27.1 \\
\hline Molluscum contagiosum & 36 & 17.1 \\
\hline Corneal ulceration & 17 & 8.1 \\
\hline Squamous cell carcinoma & 13 & 6.2 \\
\hline Herpes zoster ophthalmicus & 7 & 3.3 \\
\hline Cataract & 6 & 3.0 \\
\hline $\begin{array}{l}\text { Kaposi sarcoma involving the lids, } \\
\text { conjunctiva and nose }\end{array}$ & 3 & 1.4 \\
\hline TOTAL & 210 & 100 \\
\hline
\end{tabular}

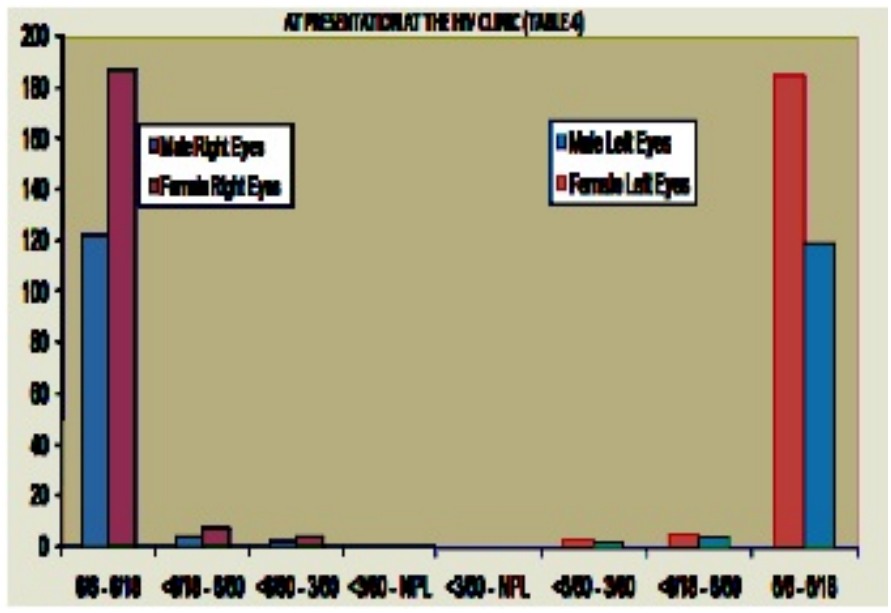

Figure 1. Histogram of visual acuity of patients at presentation at HIV clinic.

Figures 2-6 show ocular adnexal and anterior segment lesions seen in HIV / AIDS patients at presentation to the clinic. 


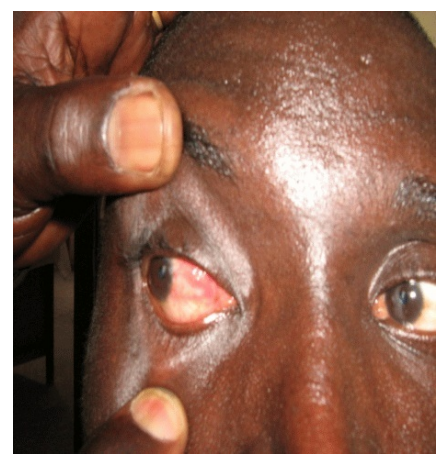

Figure 2. Conjunctival microangiopathy

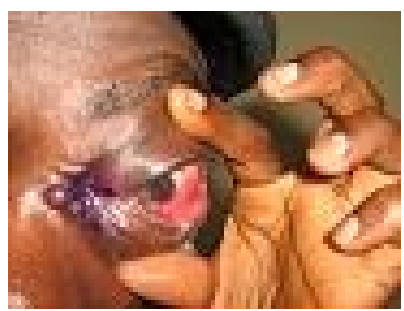

Figure 4. Advanced squamous cell carcinoma

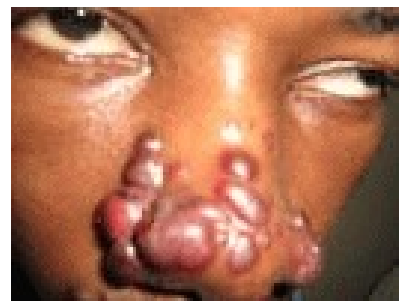

Figure 6. Karposi sarcoma

\section{DISCUSSION}

HIV / AIDS constitutes a major threat to humanity in the $21^{\text {st }}$ century. The current national prevalence rate for Nigeria is put at $5.8 \% .^{3}$ Benue State, where this study was undertaken, has the highest prevalence rate $(16.8 \%)$ among the hyperendemic zones of Nigeria. ${ }^{4}$ This study highlights the effects of HIV / AIDS on the ocular adnexal and anterior segments of infected patients and evaluates the effect on visual functions. The female to male ratio in this study was 1:1.5.

The prevalence rate of $65.2 \%$ for affected anterior segment in this study is not surprising as the clinic is an exclusively HIV / AIDS clinic, sited in a hyper-endemic area, which also serves other hyper-endemic states like Cross River and Kogi states. Previous studies from other zones in Nigeria - Kaduna in the North Central zone and Ile Ife and Benin in the South West zone - show comparatively lower prevalence rates $12.3 \%, 28.8 \%$ and $21 \%$ respectively. ${ }^{13,14,17}$

This study showed that $95.1 \%$ of the subjects had normal visual acuity while $1.7 \%$ had severe visual impairment. This is in contrast to $23 \%$ bilateral blindness found by Nwosu, ${ }^{16}$ in his series from Onitsha, southeast Nigeria. This may have been because his patients had more severe anterior segment lesions (herpetic ulcers, ocular palsy and trauma), coupled with advanced posterior segment lesions.

Conjuctival microangiopathy was the most common lesion $(33.8 \%)$ seen in this series. Teish ${ }^{21}$ and Egestrome, ${ }^{22}$ found conjunctival microangiopathy accounting for $70 \%$ and $80 \%$ in their respective studies. The main features of the lesions were segmental vascular dilatation, corkscrewshaped deformities, comma-shaped vascular sections, vascular sludging of blood, microaneurisms, dilatation and narrowing of conjunctival vessels. There is increased plasma viscosity, immune complex deposit and probably direct invasion of the conjunctival endothelium by the HIV virus. In a related microangiopathy found in the retina in other studies, $^{23}$ it has been documented that the retinal microangiopathy was closely related to the degree of viral load and less correlated to the degree of immunodeficiency. ${ }^{23}$ Similarly, the pathological condition of thrombotic microangiopathy found in HIV 1 and HIV 2 infections, a viral specific factor has been implicated in the pathogenesis of HIV associated thrombomicroangiopathy. ${ }^{24}$ Whether the pathogenesis postulated in the last two conditions is similar to the aetiology of conjunctival microangiopathy seen in this study is a subject for further studies. Less severe forms of conjunctival microangiopathies are occasionally seen as

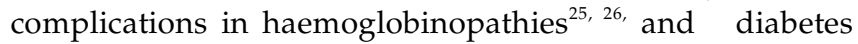
mellitus. ${ }^{27}$ None of the subjects in this study had sickle cell disease or diabetes mellitus. Nutritional anaemia could be a possible cause of the conjunctival angiopathy seen in this study. The average PCV of the patients at presentation to the clinic was $25 \%$ and below.

Iridocyclitis was the second most common anterior segment manifestation in this study. It affected $27.1 \%$ of the patients with lesions. The majority of these cases were idiopathic and could be part of generalized autoimmune and endogenous uveitis. Ebanu ${ }^{28}$ in Cameroon found iridocyclitis/uveitis the most common anterior segment presentation in his series $(18.8 \%)$. Nwosu ${ }^{16}$ recorded that iridocyclitis/uveitis accounted for $4 \%$ in his study. Immune recovery uveitis is a condition that is due to increased intraocular inflammation associated with cytomegalovirus retinitis in patients with improved immune system following treatment with highly active antiretroviral therapy (HAART) ${ }^{29,30}$ Immune recovery uveitis did not apply to subjects in this study because none of them had commenced HAART treatment at the time of this work.

Molluscum contagiosum accounted for lesions seen in $17.1 \%$ of affected patients in this study. It is caused by a DNA pox virus which is spread by direct contact with infected persons or by formites. Molluscum contagiosum is more frequent and severe in patients who are HIV positive. In this study, $25 \%$ of the lesions were found on the lids. Cunningham ${ }^{10}$ reported in his series a $5 \%$ affectation of the lids by molluscum contagiosum. 
Corneal ulceration accounted for the adnexal / anterior segment disorders in $8.1 \%$ of the patients in this study. Herpes zoster keratitis leading to corneal ulcerations accounted for $6.6 \%$ of the causative factors for corneal ulcerations. The rest were the sequelae of corrosive herbal medication applied to the eye for ocular complaints.

Squamous cell carcinoma accounted for ocular manifestation of HIV / AIDS in $6.2 \%$ of affected patients. This makes it the fifth most common ocular finding in this work. Squamous cell carcinoma was the second most common anterior segment lesion seen in an ophthalmic clinic in Harare. Two out of every hundred HIV / AIDS patients had squamous cell carcinoma. ${ }^{31,32}$

Contrary to the findings from previous studies ${ }^{13,14,17,33}$ from other parts of the country, which found herpes zoster ophthalmicus to be the commonest ocular manifestation of HIV infection, in this study it accounted for only 3.3\% of cases. It was the sixth commonest ocular adnexal and anterior segment lesion found in this series. Even though herpes zoster ophthalmicus is the marker for HIV infection in Africa, ${ }^{16,18,19,33}$ in this study, only seven (7) cases were seen out of the 210 patients with lesions. The low incidence may not be unconnected with the fact that there are other established centres that cater for HIV-infected patients in the state.

Senile cataract was seen in $3 \%$ of the cases, while complicated cataract resulting from the complications of uveitis/iridocyclitis were seen in $66.7 \%$ of the affected patients in this study.

Kaposi sarcoma is a highly vascular tumour appearing as nodules on the lids, face and conjunctiva. It accounted for lesions in $1.4 \%$ of the cases in this study. In one of the patients, there were multiple severe lesions on the lids and nose. Other studies ${ }^{34}$ have documented Kaposi sarcoma as high as $25 \%$ in their findings.

In this study, $95.1 \%$ of the patients had normal visual acuity at recruitment point, $3.2 \%$ had visual impairment, while $1.7 \%$ had severe visual impairment. None of the patients presented with blindness. Female patients tended to present with worse visual acuity compared to male patients. This may not be unconnected with financial limitations since most housewives depend on their husbands for medical expenses.

\section{CONCLUSION AND RECOMMENDATION}

Herpes zoster ophthalmicus has been reported as the most prevalent ocular and adnexal presentation of HIV infection from earlier works. ${ }^{13,14,18,33}$ This is at variance with the finding in this study. Conjunctival microangiopathy was the most common ocular adnexal and anterior segment manifestation. It accounted for $33.8 \%$ of cases. This was followed by iridocyclitis, $27.1 \%$ and molluscum contagiosum $17.1 \%$. Herpes zoster ophthalmicus accounted for only 3.3\% of adnexal and anterior segment disorders. Kaposi sarcoma was the least common accounting for $1.4 \%$ of cases. It is apparent that most of the ocular adnexal and anterior segment lesions seen in HIV-AIDS patients are treatable and can be averted by timely diagnosis and management. This will help a great deal in preventing the additional burden of blindness with its numerous socioeconomic implications.

\section{REFERENCES}

1. Nasoodi A, Lim LT, AL-Ani A, Quah S, Dinsmore WW. What you can see in your patient's eye? Review of ocular manifestations of HIV in HAART Era. Int J STD AID 2008; 19: 4-11.

2. UNAIDS and the World Health Organization. AIDS Epidemic Update December 2007; UNAIDS/WHO 207 UNAIDS/ 07.27E JCI 322E.

3. UNAIDS/WHO, AIDS Epidemic Update December 2005; UNAIDS/WHO 2005/05/19E.

4. Adediran SO, Odimayo MS, Jimoh AK. Pattern of presentation among HIV / AIDS patients in Makurdi, Nigeria. Int J Epidemiol 2009; 6: 2-6.

5. Shisana O, Rehle T, Simbayi L, Parker W, Zuma K, Bhana A, Connolly C, Jooste S, Pillay V. South African National HIV survey 2005; HSRC Press: 2009.

6. Bila B, Egrot M. Gender asymmentry in healthcare - facility attendance of people living with HIV / AIDS in Burkina Faso. Soc Sci Med 2009; 69: 854 - 61.

7. Parkhurst JO. The Uganda success story? Evidence and claims of HIV - 1 prevention. Lancet 2002; 360: 78 - 80 .

8. Federal Ministry of Health (Nigeria). HIV/Syphilis sentinel sero positive survey in Nigeria 2001; Technical Report AID/STD Central Programme.

9. Holland GN, Gotteliebs MS, Yee RD, Schanker IIM, Pettit TH. Ocular disorders associated with a new severe acquired cellular immunodeficiency syndrome. Am J Ophthalmol 1982; 93: 392-402.

10. Cunningham ET, Margolis TP. Ocular manifestation of HIV infection. N Engl Jour Med 1998; 339(4): 236-44.

11. Sarraf D, Ernest JI. AIDS and the eye. Lancet 1996; 348: 525-28.

12. Irma A, Everet I, Eugene C, Alan A. Ophthalmic manifestation of HIV. HIV Insite Knowledge Base Chapter August 2005; Content review January 2006.

13. Kehinde AV, Samaila E. Ocular Aids: Experience at Guinness Ophthalmic Unit, Kaduna, Nigeria. Nigerian Journal of Surgical Research 2005; 7(3 and 4):305 - 8 .

14. Adegbehingbe BO. Eye, Ocular Disease in HIV/AIDS in Obafemi Awolowo University Teaching Hospital Complex, Ile-Ife. Nigerian Journal of Surgical Science 2006; 16(2): 47-53.

15. Mohammed I, Nasidi A, Chikwen JD, Williams EE, Harry TO, Okafor GO. HIV infection in Nigeria. AIDS 1988; 2: 61-2.

16. Nwosu NN. HIV / AIDS in ophthalmic patients: The Guinness Eye Centre, Onitsha experience. PMID: 18293635 [pub MED - indexed for MED LINE].

17. Osahon AI. HIV infection and herpes zoster ophthalmicus: University of Benin Teaching Hospital Eye Clinic experience. Nig J Ophthalmol 1999; 7: 1-4.

18. Akinsola FB, Okanny CC, Majekodunmi AA, Akinsete I. Ocular manifestation of HIV infection in Lagos: Lagos University Teaching Hospital experience. Nigeria Post Graduate Medical Journal 1997; 4: 84 - 7. 
19. Omoti AE, Omoti CE. Maxillary herpes zoaster with corneal involvement in a HIV positive pregnant woman. African Journal of Reproductive Health 2007; 11(1): 133-6.

20. Lightman S. HIV / AIDS. The differing ocular manifestation in developed and developing countries. Community Eye Health 1995; 8: 17 - 19 .

21. Teish SA. Conjunctival Microvascular Changes in AIDS and AIDS related complexes. Am J Ophthalmol 1987; 103: 332-3

22. Engestrom RE Jr, Holland GN, Hardy WD, Meiselman HJ Haematological anomalies in patients with human immunodeficiency virus infection and ophthalmic microangiopathy. Am J Ophthalmol 1990; 109: 153-61.

23. Furrer H, Barloggio A, Garweg J. Prevalence of microagiopathy in HIV-infection is related to higher viral load in plasma. Abst. Intersci Conf Antimicrob Agents Chermother Dec 2001;(41): abs no. I-251.

24. Jochinisen F, Gruening N, Arnorld T, Segal MS, Colgrove R, Wal G. European Renal Association May 2004; 19(5): 1129-35.

25. Bunn HF. Pathological and treatment of sickle cell disease. $N$ Engl J Med 1997; 337: 762-9.

26. Anthony TW, Peter CYN, Edward CL, Patricia LD, Sahana R, Fern T, Ted W. Microvascular abnormalities in sickle cell disease: a computerized intravitral microscopy study. Blood 2002; 99(11): 3999-4005.
27. Searle BR, Rafeal ACD, James BC, Oscar LC, Alfredo CA, Jan T, Daniel P, Jorge PK, Alexander M. Pathophysiology of microangiopathy in diabetes mellitus. Endocrinology May 2008; 15: 30.

28. Ebanu MC, Ellong A, Bella AL, Luma H, Achu JH. HIV / AIDS and the eye. Bull Soc Belge Ophthalmol 2007; 305: 7 - 12.

29. Colombero D, Agostini M, Lupo S. Immune recovery uveitis in the HAART era. Int Conf on AIDS. Bangkok, Thailand July 2004; 11-16; 15.

30. Dunn JP. Immune recovery uveitis. Hopkins HIV Report 2001; 13: 9-10.

31. Solomon G. Squamous cell carcinoma in HIV/AIDS. Community Eye Health 2003; 16: 47.

32. Muccioli C, Belfort R, Burnier M, Rao N. Squamous cell Carcinoma of the conjunctiva in a patient with acquired immune deficiency syndrome. Am J Ophthalmol 1996; 121: 94-

33. Umeh RE. Herpes zoster ophthalmicus and HIV infection in Nigeria. Int J STD/AIDS August $1998 ; 476$ - 9.

34. Angel DU, Gill PS, Frangieh GT, Rao NA. Ocular adnexal kaposi sarcoma in acquired immuno deficiency syndrome. Am J Ophthalmol 1990; 110: 500-3. 